University of Louisville

ThinkIR: The University of Louisville's Institutional Repository

Faculty Scholarship

$6-2014$

\title{
Do trust-based beliefs mediate the associations of frequency of private prayer with mental health? : a cross-sectional study.
}

\author{
Patrick Pössel \\ University of Louisville \\ University of Louisville \\ Annie C. Bjerg \\ University of Louisville \\ Benjamin D. Jeppsen \\ University of Louisville \\ Don T. Wooldridge \\ University of Louisville
}

Stephanie Winkeljohn Black

Follow this and additional works at: https://ir.library.louisville.edu/faculty

Part of the Counseling Psychology Commons

Original Publication Information

Pössel, Patrick, Stephanie Winkeljohn Black, Annie C. Bjerg, Benjamin D. Jeppsen and Don T. Wooldridge. "Do Trust-Based Beliefs Mediate the Associations of Frequency of Private Prayer with Mental Health? A Cross-Sectional Study." 2014. Journal of Religion and Health 53(3): 904-916.

This Article is brought to you for free and open access by ThinkIR: The University of Louisville's Institutional Repository. It has been accepted for inclusion in Faculty Scholarship by an authorized administrator of ThinkIR: The University of Louisville's Institutional Repository. For more information, please contact thinkir@louisville.edu. 
Do Trust-Based Beliefs Mediate the Associations of Frequency of Private Prayer with Mental Health? A Cross-Sectional Study

Dr. rer. soc. Patrick Pössel ${ }^{1}$, Stephanie Winkeljohn Black ${ }^{2}$, Annie C. Bjerg ${ }^{3}$, Benjamin D. Jeppsen $^{4}$, and Don T. Wooldridge ${ }^{5}$

Corresponding author:

Patrick Pössel, Dr. rer. soc.

Dep. of Educational and Counseling Psychology

University of Louisville

2301 S. Third Street

Louisville, KY 40292

USA

$+1-(502) 852-0623$ (office)

$+1-(502) 852-0629$ (fax)

e-mail: patrick.possel@louisville.edu

Patrick Pössel, Dr. rer. soc., is Associate Professor at the Department of Educational and Counseling Psychology, University of Louisville. His research focuses on factors preventing the development of mental health in general and of depression in particular. Within this focus he studies what mechanisms underlie the positive effects of religiousness on mental health.

\footnotetext{
${ }^{1}$ Department of Educational and Counseling Psychology, University of Louisville, Louisville, KY, USA

${ }^{2}$ Department of Educational and Counseling Psychology, University of Louisville, Louisville, KY, USA

${ }^{3}$ Department of Educational and Counseling Psychology, University of Louisville, Louisville, KY, USA

${ }^{4}$ Department of Educational and Counseling Psychology, University of Louisville, Louisville, KY, USA

${ }^{5}$ Department of Educational and Counseling Psychology, University of Louisville, Louisville, KY, USA
} 


\begin{abstract}
Significant associations of private prayer with mental health have been found, while mechanisms underlying these associations are largely unknown. This cross-sectional online study $(N=325$, age: $35.74, S D: 18.50,77.5 \%$ female $)$ used path modeling to test if trustbased beliefs (whether, when, and how prayers are answered) mediated the associations of prayer frequency with the Anxiety, Confusion, and Depression Profile of Mood States-Short Form (POMS) scales. The association of prayer and Depression was fully mediated by trustbased beliefs; associations with Anxiety and Confusion were partially mediated. Further the interaction of prayer frequency by stress was association with Anxiety.
\end{abstract}

Keywords: cross-sectional; private prayer frequency; religious behavior; mental health; POMS. 


\section{Associations of private prayer with mental health}

Many authors have considered the positive relationship between private prayer and an individual's mental health. Specifically, the frequency of private prayer (to be termed prayer frequency hereafter) has been found to have a significant relationship with self-reported symptoms of mental health across different age groups (Francis, Robbins, Lewis, \& Barnes, 2008; Hebert, Dang, \& Schulz, 2007; Koenig, 2007; Meisenhelder \& Chandler, 2000a, 2000b, 2001; Thomas, 2008). For example, in a sample of Irish $6^{\text {th }}$ grade students, prayer frequency was consistently inversely associated with psychoticism in Catholic and Protestant students (Francis et al., 2008). Further, Herbert et al. (2007) demonstrated that frequency of prayer is inversely related to depression in caregivers of persons with dementia while Koenig (2007) compared inpatients with and without clinical depression and found that patients who prayed more often (more than once a day) were less likely to experience major (48\%) and minor depression (54\%) compared with patients that prayed less often. In a study with members of the Presbyterian Church, frequency of prayer was positively correlated with mental health (measured as a combination of anxiety, depression, and general well-being) in lay church members (2000a), church elders (2000b), and clergy (2001). Finally, a recent meta-analysis of 23 studies with 10,115 participants on the effectiveness of prayer indicated that prayer had a statistically significant, positive effect on mental health $(d=0.66$; Thompson, 2008).

However, other studies found a negative association between prayer frequency and mental health. For example, Flannelly, Ellison, Galek, and Koenig (2008) found with survey data from the general population that frequency of prayer was directly and significantly associated with self-reported symptoms of anxiety, depression, obsessive-compulsion, paranoid ideation, phobia, and somatization. In addition, a study with British adults found that prayer frequency directly predicted mental health (measured as a combination of anxiety, depression, social dysfunction, somatic symptoms; Maltby, Lewis, \& Day, 1999). Possible 
explanations for the inconsistent findings include but are not limited to psychometric reasons (incl. sampling error, usage of single items to measure prayer frequency, differing control variables), different associations between prayer frequency and different parts of mental health, and different associations in diverse populations (e.g., general population vs. ill samples, changes of the associations across the life span; for a detailed discussion see McCullough \& Larson, 1999).

The stress-buffer hypothesis is a possible mechanism explaining the association between prayer frequency and mental health. Stress is known to be a risk factor for a variety of mental health problems. Many variables measuring various elements of religiousness are able to reduce the negative impact of stress on mental health. For example, religious orientation (Park, Cohen, \& Herb, 1990), secure attachment to God (Ellison, Bradshaw, Kuyel, \& Marcum, 2012), spiritual life integration (Fabricatore, Handal, \& Fenzel, 2000), service attendance and religious/spiritual importance (Kasen, Wickramaratne, Gameroff, \& Weissman, 2012) were found to moderate the negative effect of stress on different parts of mental health. Further, religious coping has been specifically conceptualized to moderate the impact of stressful events on mental health (Pargament, 1997). Finally, prayer frequency seems to reduce the effect of stress on mental health as well (for a review see McCullough \& Larson, 1999). For example, a study with a nationally representative sample of adults in the United States found not only that prayer frequency predicted lower scores of self-reported anxiety, but also that prayer frequency buffered against the negative effects of stress (i.e., poor health, financial problems) on anxiety (Ellison, Burdette, \& Hill, 2009).

However, like the findings on main effects of prayer frequency, the findings in regard to prayer frequency as buffer against stress are mixed. For example, using the same sample as Ellison et al. (2009), Bradshaw and Ellison (2010) found neither a main of prayer frequency nor an interaction effect of prayer frequency with financial problems on psychological distress (measured as a combination of feeling sad, nervous, restless, hopeless, 
worthless, that everything is an effort). Further, Pargament (1997) demonstrated in his review of the literature that the stress-buffer effect of prayer frequency usually disappears when the effect of religious coping is controlled for. Moreover, a study with older adults found no significant effect of prayer frequency on the association between stressful life events and depressive symptoms (Krause, 2009); therefore, this study did not support the stress-buffer hypothesis. However, this study only examined depressive symptoms in older adults and therefore the results cannot be generalized to all persons that pray. Summarized, findings regarding prayer frequency as a moderator of stressful life events' impact on mental health are mixed. Thus, the stress-buffer hypothesis needs to be empirically explored further.

\section{Trust-based Beliefs as mechanisms in the association of prayer and mental health}

Results demonstrating the positive effects of private prayer on mental health raise the question of what mechanisms underlie these associations. Expectancy Theory (Olson, Roese, \& Zanna, 1996) predicts that when individuals get what they expect they will experience an enhanced sense of well-being. When individuals pray, they have trust-based beliefs and thus expect certain outcomes - certain responses from God, including beliefs about whether prayers are answered, when prayers are answered, and how prayers are answered (Krause, Chatters, Meltzer, \& Morgan, 2000). Krause (2004a) stated that a fulfillment of prayer expectations make the world appear to be more predictable, more comprehensible, and more orderly in the eye of that individual. Moreover, Krause suggested that getting an expected response to a prayer may create the feeling that one has a close relationship with God that, in turn, heightens one's sense of security and ultimately bolsters one's sense of well-being.

Similarly, Expectancy Theory predicts that when expected outcomes fail to materialize, individuals experiece uncertainty, confusion, anxiety, and depression (Olson, et al., 1996). Further, disconfirmation of prayer expectancies is likely to be distressful because the individual may begin to doubt his or her faith when expected answers to prayers are not forthcoming (Krause, 2004a). Research suggesting that religious doubt is associated with 
greater psychological distress supports this notion (Krause, Ingersoll-Dayton, Ellison, \& Wulff, 1999).

To date, three specific trust-based beliefs about prayer have been empirically studied. These include beliefs regarding whether prayers are answered, when prayers are answered, and how prayers are answered. Several empirical studies have confirmed the proposed associations of beliefs about prayer with mental health. Two studies have examined prayer beliefs in general. A cross-sectional study with arthritis patients found beliefs about prayer to explain $12.1 \%$ of the variance in depression and anxiety (Laird, Snyder, Rapoff, \& Green, 2004). Indirect support for the influence of trust-based beliefs about prayer comes from a longitudinal study with cardiac patients (Ai, Peterson, Tice, Bolling, \& Koenig, 2004). In this study, individuals with more religious faith (measured as high importance of religion and religiousity) had higher intentions of using private prayer to cope with the stress associated with heart surgery. This intention to pray to cope with stress predicted higher levels of hope and optimism. These findings support the face valid assumption that people who believe more in the effects of prayers are more likely to pray.

Individuals who believe prayers are answered differ in regards to when they believe a prayer is answered. A qualitative study (Krause, et al., 2000) found praying individuals had one of two beliefs concerning the when of an answer. While one group believed they will receive an answer right away, the other group believed that an answer comes precisely when it is needed most. The important distinguishing factor here is the belief that God answers prayer when God feels it is best - and the timing of God's response is ultimately in the best interest of the individual. Similar differences were found regarding how the participants believe a prayer is answered. While one group of individuals expected to get what they asked for, the other group reported to receive what they need most but not neccesarily what they asked for (Krause, 2004a). Krause identified trust in God's better judgement as the underlying theme of both flexible beliefs concerning the when and how of prayer. Flexible 
beliefs are more likely to be perceived as fulfilled and, consistent with the Expectancy Theory (Olson et al., 1996), one can expect that these flexible beliefs are associated with better mental health. Two publications using the same sample of older adults researched this hypothesis by studying the effects of the beliefs about when and how God responds to prayer on self-esteem and depressive symptoms (Krause, 2004a, 2009). Consistent with the Expectancy Theory, trust-based beliefs about prayer, but not prayer frequency, showed a significant relationship with self-esteem when both of these variables were entered simultaneously in a regression analysis (Krause, 2004a). In the second publication, these beliefs about prayer in interaction with retrospectively measured lifetime trauma predicted symptoms of depression (Krause, 2009). Based on the Expectancy Theory (Olson et al., 1996) and this pattern of results, it is worth investigating whether trust-based beliefs about prayer are mediators of the effects of prayer frequency on mental health.

\section{Hypotheses}

Based on the above review (Ai, et al., 2004; Krause, 2004a, 2009; Krause et al., 1999, 2000; Laird et al., 2004; Olson et al., 1996), it was hypothesized that a higher frequency of private prayer and more trust-based beliefs about prayer would be associated with mental health (i.e., less anxiety, confusion, and depression). Additionally, it was hypothesized that trust-based beliefs about prayer would mediate the association of prayer frequency with mental health. However, mental health is a complex construct that is influenced by a multitude of biological, psychological, and social factors (e.g., Cichetti \& Toth, 1998). Thus, it is unlikely that trust-based beliefs are the only mechanism underlying associations between prayer frequency and mental health. Therefore, it was hypothesized that trust-based beliefs would be only partial mediators. Finally, based on mixed findings in the literature (Ellison et al., 2009; Krause, 2009; Pargament, 1997), it was hypothesized that the association of stressful life situations with mental health would not be moderated by private prayer frequency (stress-buffer hypothesis). 


\section{Methods}

\section{Participants}

Participants were recruited for a cross-sectional online study (see Procedure; $N=325$ praying adults). The age of the participants ranged from 18 to 83 years (mean age: 35.74 years; SD: 18.50 years); $77.5 \%$ were female. Of these participants, $88.0 \%$ were EuropeanAmerican, 5.8\% were African-American, 2.2\% were mixed racial, 1.8\% identified as "other," $1.2 \%$ were Asian-American, $0.3 \%$ were Hispanic, $0.3 \%$ were Native American, and $0.3 \%$ did not report any race/ethnicity. The participants represented 16 different Christian and nonChristian denominations (30.5\% of the participants identified as Christian, NonDenominational, followed by $17.2 \%$ Catholic, $15.7 \%$ Methodist, $9.2 \%$ Church of Jesus Christ of Latter-Day Saints, $8.6 \%$ Baptist, and $6.0 \%$ as belonging to another Christian denomination, 1.8\% Agnostic, $1.5 \%$ Jewish, $0.3 \%$ Muslim, $0.3 \%$ Buddist). Finally, $4.9 \%$ of the participants identified as belonging to an unlisted denomination, and 3.4\% reported no affiliation to any denomination.

\section{Measures}

Frequency of Private Prayer. Individuals responded on a 7-point likert scale (never to several times a day) to the item "On average, how often would you say that you prayed during the past year, other than during a church (synagogue) service or grace before meals?" to indicate how often they pray (Poloma \& Pendleton, 1989).

Trust-based Beliefs about Prayer. Three items developed by Krause (2004b) measured participants' beliefs about private prayer. These items assessed whether participants believed their prayers are answered ("When you pray by yourself, how often is your prayer answered?") as well as when (“Learning to wait for God's answer to my prayer is an important part of my faith.") and how ("When I pray, God does not always give me what I ask for because only God knows what is best.”). Responses were measured on a 4-point Likert scale (never to regularly; strongly agree to strongly disagree, respectively). The items 
were coded in a way that higher scores indicated more trust-based beliefs about prayer. The responses to the three items were averaged to form the Trust-based Beliefs about Prayer scale with an internal consistency of $\alpha=.73$.

Stressful Life Events. The Social Readjustment Rating Scale (SRRS; Holmes \& Rahe, 1967) was used to measure stressful life events. Consisting of 43 life events, participants were instructed to identify each life event they have experienced in the past 12 months. Each life event has a corresponding weighted value called Life Change Units (LCU's; Miller \& Rahe, 1997). Higher LCU values indicate higher stress levels, and the LCU values of identified items were summed to determine the total SRRS score. Holmes and Rahe (1967) tested the validity of the LCU's by correlating the ranks of the life events across various demographic groups (e.g., ethnicity, age, marital status, religious affiliation). With correlations from .82 (between European American and African American participants) to .98 (between second and third generation Americans), the SRRS has good validity.

Mental Health. The Profile of Mood States-Short Form (POMS-SF; Schacham, 1983) is a common measure of psychological distress and was used in the current study to assess overall mental health. The POMS-SF has 37 items, where each item is a word describing a specific feeling (e.g., tense, angry, worn out, etc.). Participants were instructed to answer how often they had each feeling within the past two weeks by answering on a 5point Likert scale (not at all to extremely). The POMS-SF has six scales: Anger, Anxiety, Confusion, Depression, Fatigue, and Vigor, which were scored by summing the participant's responses (Shacham, 1983). However, only the Anxiety, Confusion, and Depression scales were analyzed in the present study. Internal consistencies for these scales of the POMS-SF were $\alpha=.86$ for Anxiety, .78 for Confusion, and .91 for Depression.

\section{Procedure}

Participants were recruited using multiple online tools (including activities announcements by email at two large universities and a Baptist Theological Seminary, and 
listservs of multiple psychological and counseling organizations). Emails, online postings, and announcements described the aim of the study as exploring the association between mood and prayer. Interested individuals were asked to use a provided link to go to an online questionnaire (surveymonkey). A preamble including a detailed description of the study, its aims, and the risks and benefits of participating in the study was placed at the beginning of the online questionnaire. Only after reading the preamble and agreeing to the participation were individuals able to respond to the items of the online study. Data for the presented analyses were collected from June 2011 to January 2012. The participants did not receive any compensation for their participation, and the study was approved by the Institutional Review Board of the University of Louisville.

\section{Data Analysis}

To test the hypotheses, three path models were tested with the maximum likelihood method using AMOS 20.0 (Arbuckle, 1999). In one model, frequency of prayer, stress, the frequency of prayer by stress interaction, and trust-based beliefs predicted the POMS scales independently from each other (direct effect model). In the second model, frequency of prayer, stress, and the frequency of prayer by stress interaction predicted the trust-based beliefs, which predicted the POMS scales (full mediation model). Finally, in the third model, frequency of prayer, stress, and the frequency of prayer by stress interaction predict trustbased beliefs, and frequency of prayer, stress, frequency of prayer by stress interaction, and trust-based beliefs predicted the POMS scales (partial mediation model). The kurtosis, but not the skewness, of the prayer by stress interaction (3.375) and the POMS depression scale (3.728) demonstrated that both variables are non-normally distributed (> 2). In addition, the

multivariate kurtosis (40.107) demonstrated severe non-normality (>10). Thus, the goodness of fit of the models to the data was tested using Bollen-Stine bootstrapping (Bollen \& Stine, 1992) with 2000 bootstraps (Nevitt \& Hancock, 1997). However, as the Bollen-Stine bootstrapping $\mathrm{p}$ is sensitive to the number of participants in the study, it was complemented 
with the root mean squared of the residuals (RMSEA; Steiger \& Lind, 1980), and the comparative fit index (CFI; Bentler, 1990).

Each of these measures for goodness of fit and parsimony has specific parameters that need be considered. Statistically nonsignificant values of $\chi^{2}$ indicate a good fit of the model to the data. A CFI value of $\geq .95$ demonstrates good model fit and values $>.90$ are acceptable (Hu \& Bentler, 1999). An RMSEA value of $<.05$ is considered a good model fit, and values $<.08$ are acceptable (Hu \& Bentler, 1999). To compare the models $\Delta$ CFI was calculated by subtracting the CFI value of one model from the CFI value of another model. When $\triangle \mathrm{CFI}$ of two models is $>.002$ the model with higher CFI fits the data significantly better. However, when $\Delta$ CFI is $\leq .002$ both models fit equally well from a statistical point of view and the more parsimonious model should be accepted (Meade, Johnson, \& Braddy, 2008). For the purpose of the present study, the (direct, indirect, and total) effects between prayer frequency and the prayer frequency by stress interaction were crucial. Thus, when the model fit was good, the effects were inspected. In order to test the hypothesized multiple mediators, the approach of Preacher and Hayes (2008) was followed by calculating 95\% bootstrapping confidence intervals (CI) using the bias-corrected percentile method. The results regarding mediation effects were interpreted using Zhao, Lynch, and Chen's (2010) rules regarding types of mediation and non-mediation.

\section{Results}

Descriptive data and correlations for all measures are presented in Table 1. All POMS scales correlated significantly in the expected direction with each other. Thus, in all path models the POMS scales were allowed to correlate with each other. As expected, prayer frequency correlated significantly and positively with trust-based beliefs about prayer. Also as expected, prayer frequency had a negative, significant correlation with the POMS scales Anxiety, Confusion, and Depression. While stress had a significant, positive correlation with all three POMS scales, it did not correlate significantly with prayer frequency. Moreover, as 
expected, stress did not correlate significantly with trust-based beliefs about prayer. Finally, trust-based beliefs about prayer correlated significantly with all three POMS scales in the expected directions.

To identify the model that fit the data best, the direct effect model, Bollen-Stine bootstrap $p<.001$, CFI (0.870), RMSEA (0 .273), the full mediation model, Bollen-Stine bootstrap $p<.001$, CFI (0.947), RMSEA (0 .111), and the partial mediation model (Figure 1), Bollen-Stine bootstrap $p=.136$, CFI (0.998), RMSEA (0 .061), were tested and compared with each other. The comparison of the direct effect model with the full mediation model revealed that the full mediation model fit the data significantly better than the direct effect model, $\Delta \mathrm{CFI}=0.077$. Further, comparing the full mediation model with the partial mediation model supported the superiority of the partial mediation model, $\Delta \mathrm{CFI}=0.028$.

In order to test for multiple mediation effects, $95 \%$ bootstrapping confidence intervals (CI), using the bias-corrected percentile method, were calculated and presented in Table 2. The direct and indirect effects of trust-based beliefs on all three POMS scales were significant and in the predicted direction. Consistent with the hypothesis, the total effects of prayer frequency on all POMS scales were significant and in the expected direction. The direct effects of prayer frequency on trust-based beliefs about prayer were all significant and positive. Further, after controlling for the beliefs about prayer, prayer frequency was significantly associated with all POMS scales but Depression (direct effects). Thus, as predicted, trust-based beliefs about prayer partially mediated the associations of prayer frequency with Anxiety and Confusion. Surprisingly, trust-based beliefs fully mediated the association of prayer frequency with Depression.

While direct effects of stress on all three POMS scales were significant and in the expected directions, stress was not significantly associated with trust-based beliefs, and therefore there were no significant indirect effects between stress and POMS scales. 
Consistent with these findings, the total effects of stress on the POMS scales were significant as well.

The prayer frequency by stress interaction was only significantly associated with Anxiety (total effect). Further, the direct effect of the prayer frequency by stress interaction on trust-based beliefs about prayer was not significant. Additionally, after controlling for beliefs about prayer, the prayer frequency by stress interaction was significantly associated with Anxiety (direct effect). However, this association was not mediated by trust-based beliefs about prayer (indirect effect).

Nevertheless, a model-implied graph was constructed to examine the nature of the association between the prayer frequency by stress interaction and Anxiety (Figure 2). The graph demonstrates that increasing prayer frequency reduced the impact of stress on anxiety. However, contrary to the stress-buffer hypothesis, this effect is stronger in participants experiencing less stressful life events than in participants experiencing higher levels of stress.

\section{Discussion}

Replicating previous literature (Ai, et al., 2004; Krause, 2004a, 2009; Krause et al., 1999, 2000; Laird et al., 2004; Olson et al., 1996), it was proposed that prayer frequency and trust-based beliefs about prayer were associated with mental health. Further, it was expected that the associations of prayer frequency with mental health were partially mediated by trustbased beliefs about prayer and, based on mixed findings in the literature (Ellison et al., 2009; Krause, 2009; Pargament, 1997), that prayer frequency would not moderate the associations of stress with mental health.

Consistent with the hypothesis and previous literature, prayer frequency was associated with all measured aspects of mental health. Moreover, prayer frequency was associated with trust-based beliefs about prayer, and trust-based beliefs about prayer were associated with anxiety, confusion, and depression. 
The findings demonstrate that the association of prayer frequency with depression is fully mediated by the trust-based beliefs about prayer (Zhao et al., 2010) and that associations of prayer frequency with anxiety and confusion are partially mediated by trust-based beliefs, which points to additional untested mediator(s) (Zhao et al., 2010).

As expected, stress was directly associated with all measures of mental health, but none of these associations were mediated by trust-based beliefs. In addition, prayer frequency moderated the effect of stress on only one of the three measures of mental health (i.e., anxiety). More specifically, prayer frequency reduced the effect of stress on anxiety especially in individuals experiencing low levels of stress. This finding is contrary to the stress-buffer hypothesis, which predicts that prayer frequency has a greater impact when individuals experience more, rather than less, stress. However, the predominant lack of significant associations between the prayer frequency by stress interaction and measures of mental health is not only consistent with Krause's results (2009), it also explains why trustbased beliefs about prayer did not mediate the associations of the prayer frequency by stress interaction with mental health.

Findings of the present study, especially the findings that trust-based beliefs about prayer only partially mediate the associations of prayer frequency with anxiety and confusion, suggest there are mediators that have not yet been investigated. The reviews of Breslin and Lewis (2008) and McCullough (1995) discuss diverse physiological, social, and spiritual/supernatural explanations for the effects of prayer on health. Additionally, aside from the tested trust-based beliefs about prayer, other intrapsychological mediators should be considered. For example, theoretical considerations and empirical research point to associations of prayer experience (Maltby, Lewis, \& Day, 2008; Poloma \& Pendleton, 1989; Salsman, Brown, Brechting, \& Carlson, 2005), perceived God-mediated control (Krause, 2005), perceived relationship with God (Kirkpatrick, Shillito, \& Kellas, 1999; Krause, 2009; Pollner, 1989), rumination (Nolen-Hoeksema, Stice, Wade, \& Bohon, 2007), self-disclosure 
(Chen \& Contrada, 2009; Frattaroli, 2006), and suppression of intrusive thoughts (Fabbro, Muzur, Bellen, Calacione, \& Bava, 1999) with mental health. Thus, researchers should consider testing these intrapsychological variables as possible mediators in the associations of prayer frequency with mental health.

Of course, it is important to consider several limitations of the present study. A notable limitation is the correlational design of the cross-sectional study. No conclusions about causal relationships between prayer frequency, trust-based beliefs, and mental health and well-being could be drawn. Another limitation is the use of only one item to measure each of the three studied trust-based beliefs about prayer. Thus, while previous studies used similar measures (Krause, 2004a, 2004b, 2009), the reliability of such measures is likely limited. Further, participation was voluntary and participants were recruited via the Internet. Thus, no information as to the recruiting rate exists and a self-selection bias is possible. This might explain the distribution of the denominations and gender of the participants. Thus, future studies should attempt to include more male and non-Christian participants to increase the generalizability of the findings.

Summarized, not only are trust-based beliefs associated with all measured aspects of mental health, they also mediate the associations between frequency of prayer and these aspects of mental health. Thus, the present findings highlight the importance of trust-based beliefs about prayer for mental health. However, the present study also provides hints to currently untested tested mediators. Therefore, future studies applying a longitudinal design should attempt to replicate the presented findings and explore other intrapsychological variables as potential mediators between prayer frequency and mental health. 


\section{References}

Ai, A. L., Peterson, C., Tice, T. N., Bolling, S. F., \& Koenig, H. G. (2004). Faith-based and secular pathways to hope and optimism subconstructs in middle-aged and older cardiac patients. Journal of Health Psychology, 9, 435-450.

Arbuckle, J. L. (1999). AMOS user's guide. Chicago, IL: SmallWaters.

Bentler, P. M. (1990). Comparative fit indexes in structural models. Psychological Bulletin, 107, 238-246.

Bollen, K.A. and Stine, R.A. (1992). Bootstrapping goodness-of-fit measures in structural equation models. Sociological Methods and Research, 21, 205-229.

Bradshaw, M. \& Ellison, C. G. (2010). Financial hardship and psychological distress: Exploring the buffering effects of religion. Social Science \& Medicine, 71, 196-204.

Breslin, M. J., \& Lewis, C. A. (2008). Theoretical models of the nature of prayer and health: A review. Mental Health, Religion \& Culture, 11, 9-21.Chen, Y. Y., \& Contrada, R. J. (2009). Framing written emotional expression from a religious perspective: Effects on depressive symptoms. International Journal of Psychiatry in Medicine, 39, 427-438.

Cichetti, D. \& Toth, S. L. (1998). The development of depression in children and adolescents. American Psychologist, 53, 221-241.

Ellison, C. G., Bradshaw, M., Kuyel, N., \& Marcum, J. P. (2012). Attachment to God, stressful life events, and changes in psychological distress. Review of Religious Research, 53, 493-511.

Ellison, C. G., Burdette, A. M., \& Hill, T. D. (2009). Blessed assurance: Religion, anxiety, and tranquility among US adults. Social Science Research, 38, 656-667.

Fabbro, F., Muzur, A., Bellen, R., Calacione, R., \& Bava, A. (1999). Effects of prayer and a working memory task in participants trained in mediation and controls on the occurence of spontaneous thoughts. Perceptual and Motor Skills, 88, 765-770. 
Fabricatore, A. N., Handal, P. J., \& Fenzel, L. M. (2000). Personal spirituality as a moderator of the relationship between stressors and subjective well-being. Journal of Psychology and Theology, 28, 221-228.

Flannelly, K. J., Ellison, C. G., Galek, K., \& Koenig, H. G. (2008). Beliefs about life-afterdeath, psychiatric symptomology and cognitive theories of psychopathology. Journal of Psychology and Theology, 36, 94-103.

Francis, L. J., Robbins, M., Lewis, C. A., \& Barnes, L. P. (2008). Prayer and psychological health: A study among sixth-form pupils attending Catholic and Protestant schools in Northern Ireland. Mental Health, Religion, \& Culture, 11, 85-92.

Frattaroli, J. (2006). Experimental disclosure and its moderators: A meta-analysis. Psychological Bulletin, 132, 823-865.

Hebert, R. S., Dang, Q., \& Schulz, R. (2007). Religious beliefs and practices are associated with better mental health in family caregivers of patients with dementia: findings from the REACH study. American Journal of Geriatric Psychiatry, 15, 292-300.

Holmes, T.H., \& Rahe, R.H. (1967). The social readjustment rating scale. Journal of Psychosomatic Research, 11, 213-218.

Hu, L., \& Bentler, P.M. (1999). Cutoff criteria for fit indexes in covariance structure analysis: Conventional criteria versus new alternatives. Structural Equation Modeling, $6,1-55$

Kasen, S., Wickramaratne, P., Gameroff, M. J., Weissman, M. M. (2012). Religiousity and resilience in persons at high risk for major depression. Psychological Medicine, 42, 509-519.

Kirkpatrick, L.A., Shillito, D.J., \& Kellas, S.L. (1999). Loneliness, social support, and perceived relationships with God. Journal of Social and Personal Relationships, 16, $13-22$. 
Koenig, H. G. (2007). Religion and depression in older medical inpatients. American Journal of Geriatric Psychiatry, 15, 282-291.

Krause, N. (2004a). An introduction to research on religion, aging and health: Exploring new prospects and key challenges. In K. W. Schaie, N. Krause \& A. Booth (Eds.), Religious influences on health and wellbeing in the elderly. (pp. 1 - 19). New York, NY: Springer.

Krause, N. (2004b). Assessing the relationships among prayer expectancies, race, and selfesteem in late life. Journal for the Scientific Study of Religion, 43, 395-408.

Krause, N. (2005). God-mediated control and psychological well-being in late life. Research on Aging, 27, 136-164.

Krause, N. (2009). Lifetime trauma, prayer, and psychological distress in late life. International Journal for the Psychology of Religion, 19, 55-72.

Krause, N., Chatters, L. M., Meltzer, T., \& Morgan, D. L. (2000). Using focus groups to explore the nature of prayer in late life. Journal of Aging Studies, 14, 191-212.

Krause, N., Ingersoll-Dayton, B., Ellison, C. G., \& Wulff, K. M. (1999). Aging, religious doubt, and psychological well-being. The Gerontologist, 39, 525-533.

Laird, S. P., Snyder, C. R., Rapoff, M. A., \& Green, S. (2004). Measuring private prayer: Development, validation, and clinical application of the multidimensional prayer Inventory. International Journal for the Psychology of Religion, 14, 251-272.

Maltby, J., Lewis, C. A., \& Day, L. (1999). Religious orientation and psychological wellbeing: The role of the frequency of personal prayer. British Journal of Health Psychology, 4, 363-378.

Maltby, J., Lewis, C. A., \& Day, L. (2008). Prayer and subjective well-being: The application of a cognitive-behavioural framework. Mental Health, Religion \& Culture, 11, 119129. 
McCullough, M. E. (1995). Prayer and health: Conceptual issues, research review, and research agenda. Journal of Psychology and Theology, 23, 15-29.

McCullough, M. E. \& Larson, D. B. (1999). Prayer. In W. R. Miller (Ed.), Integrating Spirituality into Treatment. (pp. 85 - 110). Washington, DC: American Psychological Association.

Meade, A. W., Johnson, E. C., \& Braddy, P. W. (2008). Power and sensitivity of alternative fit indices in tests of measurement invariance. Journal of Applied Psychology, 93, $568-592$.

Meisenhelder, J. B., \& Chandler, E. N. (2000a). Prayer and health outcomes in church members. Alternative Therapies in Health and Medicine, 6, 56-60.

Meisenhelder, J. B., \& Chandler, E. N. (2000b). Prayer and health outcomes in church lay leaders. Western Journal of Nursing Research, 22, 706-716.

Meisenhelder, J. B., \& Chandler, E. N. (2001). Frequency of prayer and functional health in Presbyterian pastors. Journal for the Scientific Study of Religion, 40, 323-329.

Miller, M.A., \& Rahe, R. H. (1997). Life changes scaling for the 1990's. Journal of Psychosomatic Research, 43, 279-292.

Nevitt, J. \& Hancock, G.R. (1997). Relative performance of rescaling and resampling approaches to model Chi-square and parameter standard error estimation in structural equation modeling. Annual Meeting of the American Educational Research Association. San Diego, CA, US.

Nolen-Hoeksema, S., Stice, E., Wade, E., \& Bohon, C. (2007). Reciprocal relations between rumination and bulimic, substance abuse, and depressive symptoms in female adolescents. Journal of Abnormal Psychology, 116, 198-207.

Olson, J. M., Roese, N. J., \& Zanna, M. P. (1996). Expectancies. In E. T. Higgins \& A. W. Kruglanski (Eds.), Social psychology: Handbook of basic principles. (pp. 211-238). New York, NY US: Guilford Press. 
Pargament, K. (1997). The psychology of religion and coping: Theory, research, practice. New York, NY, US: Guilford Press.

Park, C., Cohen, L. H., \& Herb, L. (1990). Intrinsic religiousness and religious coping as life stress moderators for Catholics versus Protestants. Journal of Personality and Social Psychology, 59, 562-574.

Pollner, M. (1989). Divine relations, social relations, and well-being. Journal of Health and Social Behavior 30, 92-104.

Poloma, M. M., \& Pendleton, B. F. (1989). Exploring types of prayer and the quality of life. Review of Religious Research, 31, 46 - 53.

Preacher, K. J., \& Hayes, A. F. (2008). Asymptotic and resampling strategies for assessing and comparing indirect effects in multiple mediator models. Behavior Research Methods, 40, 879-891.

Salsman, J. M., Brown, T. L., Brechting, E. H., \& Carlson, C. R. (2005). The link between religion and spirituality and psychological adjustment: The mediating role of optimism and social support. Personality and Social Psychology Bulletin, 31, 522535.

Seligman, M. E. P., \& Csikszentmihalyi, M. (2000). Positive psychology: An introduction. American Psychologist, 55, 5-14.

Shacham, S. (1983). A shortened version of the Profile of Mood States. Journal of Personality Assessment, 47, 305-306.

Steiger, J. H., \& Lind, J. M. (1980, May). Statistically based tests for the number of common factors. Paper presented at the Psychometrika Society meeting, Iowa City, Iowa.

Thompson, D. P. (2008). A meta-analysis on the efficacy of prayer. ProQuest Information \& Learning, US.

Zhao, X., Lynch, J. G., \& Chen, Q. (2010). Reconsidering Baron and Kenny: Myths and truths about mediation analysis. Journal of Consumer Research, 37, 197-206. 
Table 1

Descriptive Data of and Correlations between Prayer frequency, Trust Beliefs, Stress, and Mental Health.

\begin{tabular}{|c|c|c|c|c|c|c|}
\hline & Frequency & $\begin{array}{l}\text { Trust-based } \\
\text { Beliefs }\end{array}$ & Stress & Anxiety & Confusion & Depression \\
\hline Trust-based Beliefs & $.51 * *$ & & & & & \\
\hline Stress & -.08 & -.01 & & & & \\
\hline Anxiety & $-.29 * *$ & $-.25 * *$ & $.24 * *$ & & & \\
\hline Confusion & $-.27 * *$ & $-.23 * *$ & $.20 * *$ & $.74 * *$ & & \\
\hline Depression & $-.19 * *$ & $-.21 * *$ & $.20 * *$ & $.72 * *$ & $.74 * *$ & \\
\hline Mean & 5.33 & 3.12 & 379.86 & 12.65 & 9.22 & 12.59 \\
\hline$S D$ & 1.77 & 0.71 & 241.73 & 4.77 & 3.60 & 5.37 \\
\hline Range & $0-7$ & $1-4$ & 0-1192 & $5-27$ & $5-24$ & $7-35$ \\
\hline
\end{tabular}


Table 2

Confidence Intervals for Multiple Mediation Effects.

Effects

Lower CI Upper CI

\section{Total effects}

Frequency - Anxiety

$-0.740 * * * \quad-1.024$

$-0.477$

Frequency - Confusion

$-0.515^{* * *}$

$-0.743$

$-0.307$

Frequency - Depression

$-0.537 * * *$

$-0.899$

$-0.244$

Stress - Anxiety

$0.003 * *$

0.001

0.005

Stress - Confusion

$0.002 *$

0.000

0.005

Stress - Depression

$0.004 * *$

0.001

0.007

Frequency by Stress - Anxiety

$0.002 * *$

0.001

0.003

Frequency by Stress - Confusion

0.000

$-0.001$

0.001

Frequency by Stress - Depression

0.000

$-0.001$

0.002

\section{Direct effects}

Frequency - Trust-based beliefs

$0.206^{* * *}$

0.151

0.257

Frequency - Anxiety

$-0.557 * * *$

$-0.848$

$-0.278$

Frequency - Confusion

$-0.375^{* *}$

$-0.617$

$-0.151$

Frequency - Depression

$-0.291$

$-0.636$

0.041

Stress - Trust-based beliefs

0.000

0.000

0.000

Stress - Anxiety

$0.003^{* *}$

0.001

0.005

Stress - Confusion

$0.003 * *$

0.001

0.005

Stress - Depression

$0.004 * *$

0.001

0.007

Frequency by stress - Trust-based beliefs

0.000

0.000

0.000

Frequency by stress - Anxiety

$0.002 * *$

0.000

0.002

Frequency by stress - Confusion

0.000

$-0.001$

0.001 
Frequency by stress - Depression

Trust-based beliefs - Anxiety

Trust-based beliefs - Confusion

Trust-based beliefs - Depression

\section{Indirect effects}

Frequency - Anxiety

Frequency - Confusion

Frequency - Depression

Stress - Anxiety

Stress - Confusion

Stress - Depression

Frequency by stress - Anxiety

Frequency by stress - Confusion

Frequency by stress - Depression

$$
0.000
$$$$
-0.890^{*}
$$$$
-0.681 *
$$$$
-1.194 * *
$$

$-0.001$

$-1.699$

$-1.300$

$-2.236$

$\begin{array}{lll}-0.183 * & -0.388 & -0.036 \\ -0.140 * & -0.277 & -0.032 \\ -0.246^{* *} & -0.484 & -0.076 \\ 0.000 & -0.001 & 0.000 \\ 0.000 & 0.000 & 0.000 \\ 0.000 & -0.001 & 0.000 \\ 0.000 & 0.000 & 0.000 \\ 0.000 & 0.000 & 0.000 \\ 0.000 & 0.000 & 0.000\end{array}$

Note . Frequency = Prayer frequency; Trust-based Beliefs = Trust-based beliefs about prayer;

Stress $=$ Social Readjustment Rating Scale; Frequency $\mathrm{x}$ stress $=$ Prayer frequency by stress interaction; Anxiety = POMS Anxiety scale Confusion = POMS Confusion scale; Depression $=$ POMS Depression scale. ${ }^{*} p<.05 ; * * p<.01 ; * * * p<.001$. 


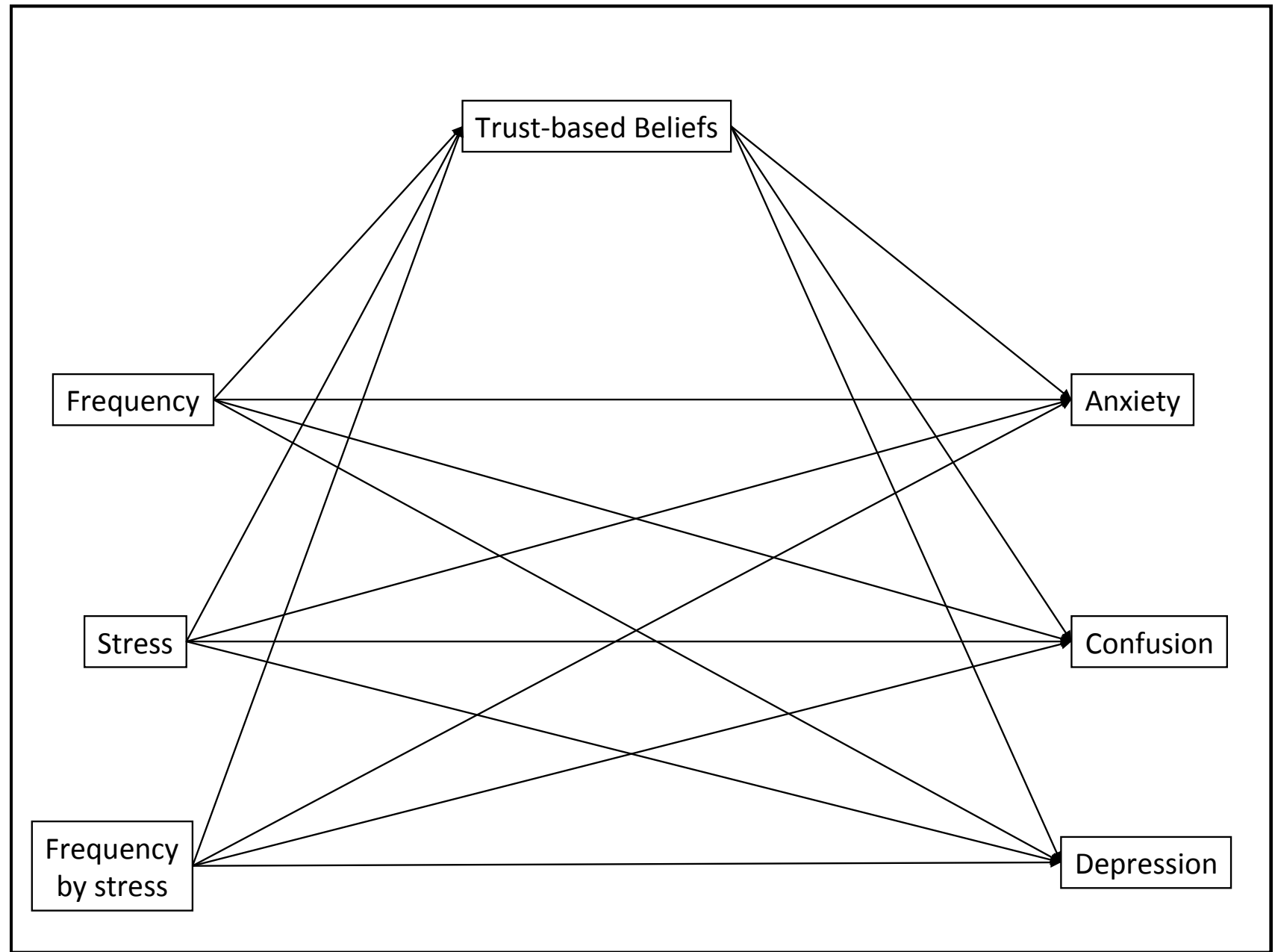

Figure 1. Proposed model in that beliefs about prayer partially mediate the associations between prayer frequency and POMS scales. Prayer frequency, stress, and the prayer frequency by stress interaction, the three beliefs about prayer and all three POMS scales are correlations with each other. These correlations are not pictured for reasons of clarity. 


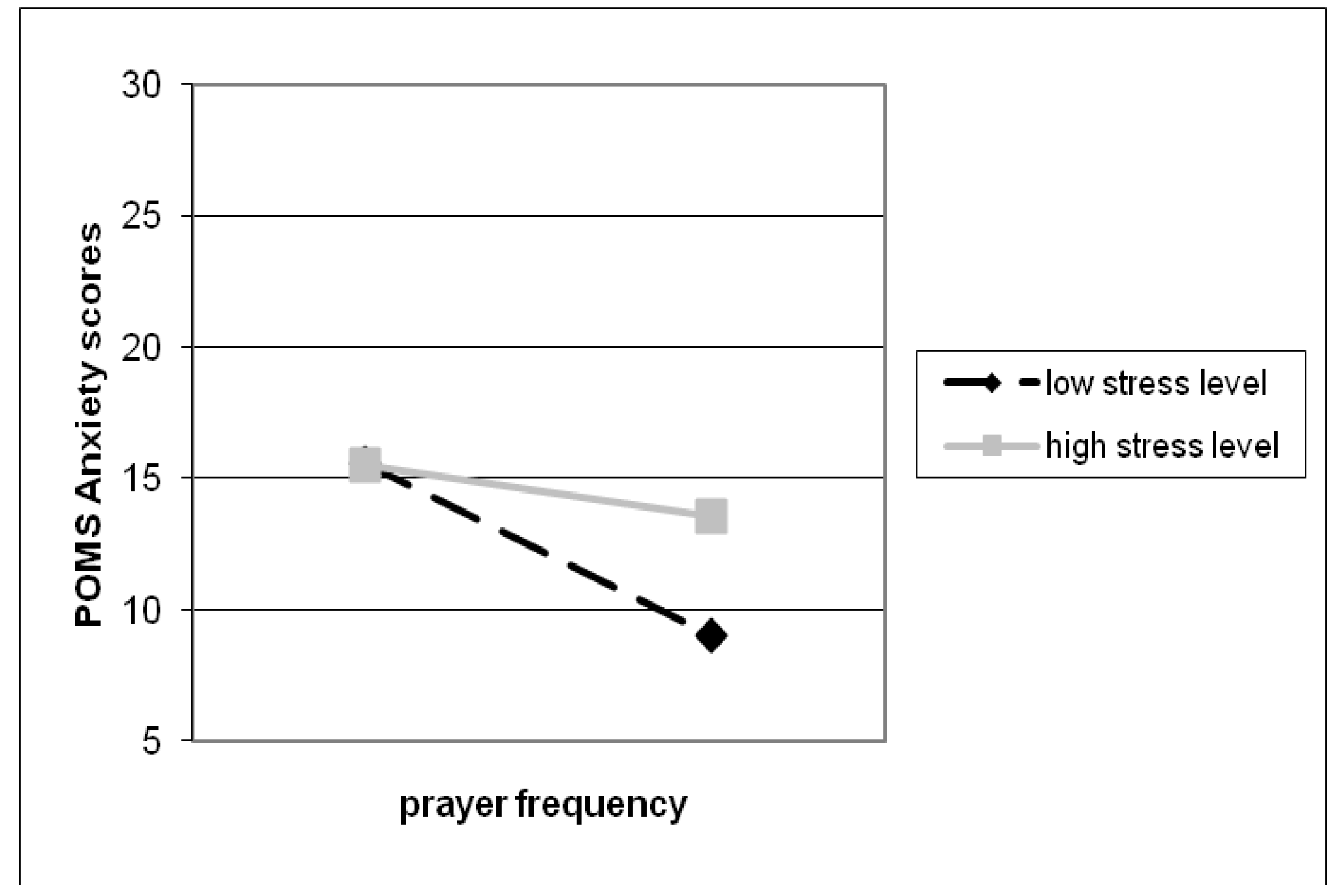

Figure 2. Model implied graph of the standardized prayer frequency by stress interaction effect on the POMS Anxiety scale. 